\title{
Scan Features of Brain Damage during Trauma in Kinshasa, Democratic Republic of Congo: A Case Series Study
}

\author{
Samuel Bula Mbaki ${ }^{1}$, Aliocha Natuhoyila Nkodila ${ }^{2,3}$, \\ Michel Tshikwela Lelo ${ }^{1}$, Benjamin Mbenza Longo ${ }^{2,4}$ \\ ${ }^{1}$ Department of Radiology, University of Kinshasa, Kinshasa, Democratic Republic of Congo \\ ${ }^{2}$ Faculty of Public Health, Lomo University Research, Kinshasa, Democratic Republic of Congo \\ ${ }^{3}$ Faculty of Family Medicine, Protestant University in Congo, Kinshasa, Democratic Republic of the Congo \\ ${ }^{4}$ Department of Internal Medecine, University of Kinshasa, Kinshasa, Democratic Republic of Congo \\ Email: *nkodilaaliocha@gmail.com
}

How to cite this paper: Mbaki, S.B., Nkodila, A.N., Lelo, M.T. and Longo, B.M. (2021) Scan Features of Brain Damage during Trauma in Kinshasa, Democratic Republic of Congo: A Case Series Study. Open Access Library Journal, 8: e7426

https://doi.org/10.4236/oalib.1107426

Received: April 15, 2021

Accepted: May 25, 2021

Published: May 28, 2021

Copyright $\odot 2021$ by author(s) and Open Access Library Inc.

This work is licensed under the Creative Commons Attribution International License (CC BY 4.0).

http://creativecommons.org/licenses/by/4.0/

\begin{abstract}
Background and aim: Brain trauma and various neurological disorders represent a significant cause of morbidity and mortality throughout the world. But data relating to this in sub-Saharan Africa is scarce. The aim of the study is to identify traumatic pathologies by CT scan in patients followed in hospitals in Kinshasa, Democratic Republic of Congo. Methods: descriptive cross-sectional study of data from the medical records of patients having performed a brain CT scan covering a period of 24 months at the University Clinics of Kinshasa and at the Biamba Marie Mutombo Hospital. There are three types of study parameters, those relating to socio-demographic data (age, sex, date of the CT scan); those relating to the clinical data and the indications for the examination and the CT data. Results: 746 presented trauma assessment against 2433 patients for a non-traumatic indication. The mean age was $47.1 \pm 20.9$ years. There was a statistically significant and unequal distribution of the proportions of indications for brain scan according to age groups: the age group $<40$ years coinciding exclusively in the traumatic assessment against non-traumatic indications for patients $\geq 60$ years of age. Of the many traumatic injuries seen on a brain scan, bone fractures, intracranial hematomas and brain contusions were the most common injuries. Conclusion: traumatic lesions on CT are frequent in Kinshasa; they are characterized by the presence of bone fractures, intracranial hematomas and cerebral contusions.
\end{abstract}

\section{Subject Areas}

Internal Medicine 


\section{Keywords}

Brain Injuries, CT Scan, Trauma, Kinshasa Hospitals

\section{Introduction}

Brain trauma and various neurological disorders represent a significant cause of morbidity and mortality across the world, with the World Health Organization (WHO) estimating that nearly one billion people worldwide live with a neurological disease [1] [2]. These traumas constitute a heterogeneous family with etiologies, anatomical substrata as well as various clinical characteristics including neurodegenerative diseases and neurological disorders of development [3]. They are of paramount importance because of the vital risk they represent, the functional impotence they cause, and the long-term treatment they require. Their repercussions, directly or indirectly, significantly affect all of society and are believed to be responsible for $35 \%$ of overall disease-related spending worldwide [1] [4].

In emergency and after transfer of patients to a specialized service, the diagnosis of cranioencephalic pathologies (PCE) is based on a set of clinical instruments (semiology and physical examination) correlated with a complementary assessment including constantly dynamic and innovative neurological imaging. The place of imaging is therefore crucial since it allows in particular to improve patient care. It specifies the etiological and differential diagnosis, the location of the lesions, the anatomo-clinical consistency of the picture while guiding the management as well as the therapeutic follow-up [1] [3].

From this perspective, new techniques for exploring the cerebral parenchyma, in particular computed tomography (CT) and magnetic resonance imaging (MRI) are of primary interest by allowing a morphological and functional study of the brain in Kinshasa [1]. The objective of this study is to identify traumatic pathologies by CT scan in patients followed in hospitals in Kinshasa, Democratic Republic of Congo.

\section{Material and Methods}

This was a cross-sectional study with descriptive approaches to data from the medical records of patients with brain CT. This study covered the period from January 1, 2014 to December 31, 2015, a period of 24 months. It was carried out in the city of Kinshasa, at the University Clinics of Kinshasa in the Commune of Lemba and at the Biamba Marie Mutombo Hospital in the Commune of Masina. These medical trainings served the needs of a large part of the population of the city of Kinshasa.

The study population consisted of patients referred for CT brain scan, of all ages and without gender discrimination during the study period. Any patient who performed a brain CT examination with a file containing data on the para- 
meters of interest and presenting a documented diagnosis by CT scan was included. Patients referred to the imaging department for a CT scan other than brain CT and those with a non-usable record were excluded in the study. A total of 3179 patients fulfilling the inclusion criteria were included in this study. Among the 3179 brain CT scans retained in this study, 600 computed tomography examinations were considered in the evaluative and comparative analysis, including 300 indicated for trauma assessment.

Data for the present study were collected from patient charts referred for CT brain scan with documented CT scan diagnosis. There are three types of study parameters, those relating to socio-demographic data (age, sex, date of the CT scan); those relating to clinical data and indications for the examination and those relating to CT data.

From a technical point of view, the examination was performed on a subject in the supine position, arms alongside the body, the head fixed in the headrest to obtain perfect immobilization. The head was placed face on following luminous markers. The obliquity of the section plane was chosen after carrying out a scout-view (digital x-ray of the skull in profile). All the examinations, apart from the exploration of the sella turcica, were carried out in an $8 \mathrm{~mm}$ section in the supra-tentorial and $5 \mathrm{~mm}$ in the sub-tentorial following the orbital-meatal plane (OM) going from the upper edge of the ductus external auditory nasion. The injection of contrast product was not systematic and was done as appropriate depending on the indication or the clinical question asked. As part of the evaluative approach, the CT images were re-read by the principal investigator (MBB) according to the usual semiology with reading in a parenchymal and bone window under the supervision of the sponsor (LTM).

\section{Statistical Analyzes}

The data was collected in a register and entered into a database created in Excel 2013 with a personal microcomputer. They were imported to be organized, analyzed and processed on the IBM Statistical Package for the Social Sciences (SPSS) version 23 software running on a Microsoft Windows 8 platform. Statistical calculations made it possible to obtain the averages with deviations. types (ET), absolute and relative frequencies. The results have been presented in the form of tables and figures. Descriptive statistics presented quantitative variables as means \pm standard deviations and qualitative variables as numbers $(\mathrm{n})$ and proportions (\%). Statistical inference was applied for an analytical approach through the comparisons. Student's t test was used for comparison of means for qualitative variables of interest. The $\mathrm{p}$-value $<0.05$ was considered to be the level of statistical significance.

The three principles of research ethics were respected, namely respect for the human person, beneficence and justice. Respect for the human person was ensured by the anonymity of the collection sheets replaced by a code known only to the investigator; beneficence was ensured by confidentiality of data, no information of newborns or mothers was disclosed to third parties. Respect for justice 
was ensured by the free consent of patients to participate in the study and the right of withdrawal if that annoyed the respondents. Before initiating this research, its protocol was presented and approved by the national health ethics committee in No. 113/CNES/BN/PMMF/2015 of 04/20/2015.

\section{Results}

Out of 3179 patients referred for computed tomography examination, 746 were referred for trauma assessment against 2433 patients for a non-traumatic indication.

\section{Sociodemographic characteristics}

The present study considered for evaluation a total of 3,179 of which 1,815 male cases versus 1364 female cases with predominance of the male sex. Indeed, the sex ratio was M/F: 1.33 in the entire study population.

There was a statistically significant predominance of traumatic indications in males than proportions of non-traumatic indications for cerebral CT scan $(\mathrm{p}=0.012)$. The mean age was $47.1 \pm 20.9$ years with the extremes of 1 month to 97 years. The age group of 40 to 59 years old followed by that of $\geq 60$ years and other age groups. There was a statistically significant $(\mathrm{P}<0.05)$ and unequal distribution of the proportions of indications for cerebral CT scans according to age groups: the age group $<40$ years coinciding exclusively in the traumatic assessment against non-traumatic indications for patients $\geq 60$ years of age (Table 1).

\section{CT technique}

The majority of CT examinations were performed without injection of contrast product (Table 2). Of the 754 exams with contrast injection, $98 \%$ and $2 \%$ were for single PC injection and CT angiography, respectively (Table 2).

\section{Lesions discovered}

Among many traumatic lesions observed on the brain scan $(n=598)$, bone fractures, intracranial hematomas and brain contusions were the most frequent lesions ( $\geq 15 \%)$ (Table 3, Figure 1).

Table 1. Sociodemographic characteristics according to trauma vs. no.

\begin{tabular}{ccccc}
\hline Variables & $\begin{array}{c}\text { Over all } \\
\mathbf{n}=\mathbf{3 1 7 9}(\%)\end{array}$ & $\begin{array}{c}\text { Trauma } \\
\mathbf{n}=\mathbf{7 4 6}(\%)\end{array}$ & $\begin{array}{c}\text { No trauma } \\
\mathbf{n}=\mathbf{2 4 3 3}(\%)\end{array}$ & $\mathbf{p}$ \\
\hline Gender & & & & 0.012 \\
Male & $1815(57.1)$ & $482(64.6)$ & $1333(54.8)$ & \\
Female & $1364(42.9)$ & $264(35.4)$ & $1100(45.2)$ & \\
Age & & & & \\
$\leq 19$ years & $399(12.6)$ & $164(22.0)$ & $235(9.7)$ & $<0.001$ \\
$20-39$ years & $673(21.2)$ & $287(38.5)$ & $386(15.9)$ & 0.001 \\
$40-59$ years & $1099(34.6)$ & $211(28.3)$ & $888(36.5)$ & 0.123 \\
$\geq 60$ years & $1008(31.7)$ & $84(13.3)$ & $924(38.0)$ & $<0.001$ \\
\hline
\end{tabular}


Table 2. Distribution of CT scans according to the injection or not of a contrast product.

\begin{tabular}{ccc}
\hline CT technique & Frequency & Pourcentage \\
\hline No Injection & 2426 & 76.3 \\
Rast product injection & 754 & 23.7 \\
Simple contrast medium injection & 739 & 98.0 \\
Contrast injection CT angiogram & 15 & 2.0 \\
Total & 3179 & 100.0 \\
\hline
\end{tabular}

Table 3. Traumatic lesions observed on brain CT scan.

\begin{tabular}{|c|c|c|}
\hline Lesions & $\mathbf{n}$ & $\%$ \\
\hline \multicolumn{3}{|l|}{ Primary lesions } \\
\hline Bone fracture & 176 & 29.4 \\
\hline Bone disjunction & 4 & 0.7 \\
\hline Intracranial hematoma & 135 & 22.6 \\
\hline - Under dural & 77 & 12.9 \\
\hline - Extradural & 39 & 6.5 \\
\hline - Intraparenchymal & 19 & 3.2 \\
\hline Brain contusion & 89 & 14.9 \\
\hline Contusion and scalp hematoma & 51 & 8.5 \\
\hline Intraventricular hemorrhage & 41 & 6.9 \\
\hline Arachnoid hemorrhage & 12 & 2.0 \\
\hline Diffuse axonal injury & 7 & 1.2 \\
\hline Orbital lesion & 11 & 1.8 \\
\hline Contusion & 9 & 1.5 \\
\hline - Burst & 1 & 0.2 \\
\hline - Hematoma & 1 & 0.2 \\
\hline - Retinal detachment & 1 & 0.2 \\
\hline \multicolumn{3}{|l|}{ Secondary and associated lesions } \\
\hline Pneumoencephaly & 22 & 3.7 \\
\hline Commitment & 19 & 3.2 \\
\hline - Sous-falcoriel & 13 & 2.2 \\
\hline - Tonsillus & 6 & 1.0 \\
\hline Intracranial hypertension & 21 & 3.5 \\
\hline Brain edema & 13 & 2.2 \\
\hline Post-traumatic hydrocephalus & 1 & 0.2 \\
\hline
\end{tabular}

\section{Discussion}

ECTs are potentially serious, both in the short term and in the long term with a prognosis which will depend on the circumstance of occurrence, the initial clinical 


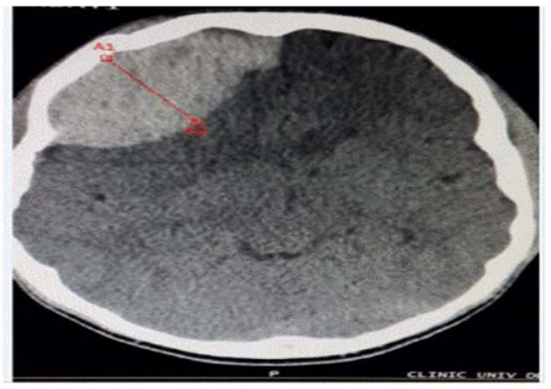

(a)

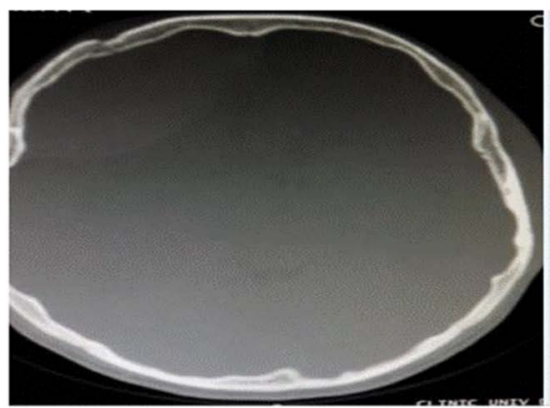

(c)

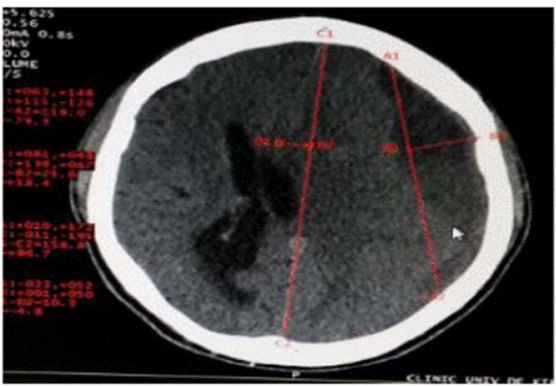

(b)

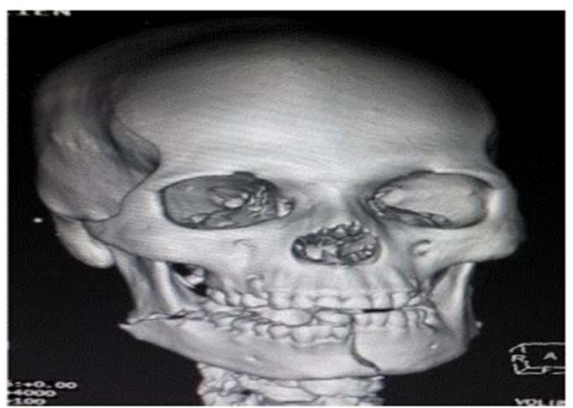

(d)

Figure 1. Traumatic lesions discovered by CT scan: (a) HED; (b) Chronic HSD; (c) Fracture next to HED; and (d) Mandibular fracture (Archives department of radiology CUK).

condition of the patient, the type of brain injury as well as the association with other traumatic injuries [5]. In this study, these different elements are not always specified, however road traffic accidents represented by far the most frequent occurrence in patients in whom the mode of occurrence was specified. This result corroborates those of African and world literature [5] [6] [7] [8].

The present study observed traumatic injury in almost half of the patients referred for CT scan for TCE. This result contrasts with that reported by Molua et al. in Kinshasa in their study between 2006 and 2010 in which $90 \%$ of patients presented at least one lesion on CT [8]. Bouvier et al. in a study on mild cranial trauma in France, 90\% of scans were found without abnormalities [9]. The disparity of these results demonstrates the difficulty in defining the indication of the brain scan for patients suffering from a particularly mild TCE, many of the brain scans or hospitalizations during the treatment of mild TCE being unnecessary [9]-[14]. Hence the growing interest in brain biomarkers as an adjunct in the management of mild and moderate head trauma [9] [15] [16]. As such, it is reported that the serum concentration of the $\mathrm{S} 100 \mathrm{~B}$ protein can play a role in the decision to perform a CT scan while behaving as a good prognostic marker for severe TCE [9] [15].

This study found a large predominance of head trauma in males and in young subjects. This result corroborates those of the majority of African and world literature [5] [10] [17]. This male predominance seems to be linked to lifestyle with risky behaviors involving more men (drugs, excessive alcohol consumption, violence, lack of compliance with road safety standards).

The present study characterized the different traumatic lesions observed on a 
brain scan; the most common in decreasing order were fractures, intracranial hematomas and brain contusions. These results corroborate those of Hode et al. in Benin [18]. On the other hand Bahloul et al. in Tunisia observed the predominance of HSA (35.2\%) and cerebral contusion (34.5\%) [19] while Seidou et al. in Niamey in Niger noted the predominance of parenchymal contusions (38\%) [5].

Two limitations can be noted in the present study, namely its retrospective nature which exposes a risk of omission of data or information bias as well as its hospital nature which does not allow the generalization of the results at the level of the entire population. from Kinshasa. However, this study has the merit of having included a larger number of patients compared to the few previous studies. Strength of the present study is that of having made available a map of the main cranioencephalic pathologies in our environment, a necessary tool for the orientation of preventive strategies and therapeutic management of cerebral pathology by health actors.

\section{Conclusion}

Traumatic lesions on CT are frequent in Kinshasa; they are characterized by the presence of bone fractures, intracranial hematomas and cerebral contusions.

\section{Acknowledgements}

We thank all who participated in the study.

\section{Authors' Contributions}

MBS and ANN designed and analyzed the statistical data for the study. LTM contributed to the data collection. LMB supervised the study. All authors have read and approved the final and revised version of the manuscript.

\section{Conflicts of Interest}

The authors declare no conflicts of interest regarding the publication of this paper.

\section{References}

[1] Claeys, A. and Vialatte, J.B. (2012) Impact et les enjeux des nouvelles technologies d'exploration et de thérapie du cerveau. Rapport Assemblée nationale française No. 4469.

[2] Comité permanent de la santé de la chambre des communes du Canada (2012) Regards sur le cerveau: Etude des maladies neurologiques au canada. Chambre des communes, Ottawa. http://www.publications.gc.ca

[3] Essourolle, R. and Poirier, J. (1977) Manuel élémentaire de neuropathologie 2ème édition. Masson, Paris.

[4] Institut du cerveau et de la moelle épinière (2017) Pathologies du cerveau: un enjeu majeur de santé publique pour le XXIème siècle.

http://www.icm-institute.org 
[5] Seidou, G., Samuila, S.S. and Abass, B. (2012) Apport de l'imagerie médicale dans le bilan des traumatismes crâniens au Niger: A propos de 331 cas à l'Hôpital National de Niamey. Journal Africain d'Imagerie Médicale, 4, 4-11.

[6] Wang, M.C., Linnau, K.F., Tirschwell, D.L. and Hollingworth, W. (2006) Utility of Repeat Head Computed Tomography after Blunt Head Trauma: A Systematic Review. Journal of Trauma, 61, 226-233. https://doi.org/10.1097/01.ta.0000197385.18452.89

[7] Gentleman, D. (1992) Causes and Effects of Systemic Complications among Severely Head Injured Patients Transferred to a Neurosurgical Unit. International Surgery, 77, 297-302.

[8] Molua, A.A., Mbongo, T.A. and Dongo, M.R. (2009) Hématomes cérébraux à Kinshasa. Imaging, 9, Article No. 18.

[9] Bouvier, D., Oddoze, C. and Ben Haim, D. (2013) Intérêt du dosage sérique de la protéine $S 100 \mathrm{~B}$ dans la prise en charge du patient après traumatisme crânien léger. Annales de Biologie Clinique, 7, 145-150.

[10] Tazarourte, K., Didane, H., Macaine, C. and Dékadjevi, H. (2007) Traumatisme crânien non grave. Collection médecine d'urgence Masson 2007: [25-200-C-10].

[11] Vialles, N., Fléchet, J., Estoro, J. and de La Coussaye, J.-E. (2003) Prise en charge d'un traumatisé crânien non grave.

[12] Carroll, L.J. (2004) Systematic Search and Review Procedures: Results of the WHO Collaborating Centre Task Force on Mild Traumatic Brain Injury. Journal of Rehabilitation Medicine, 43, 11-14. https://doi.org/10.1080/16501960410023660

[13] Banville, F. and Nolin, P. (2008) Epidémie silencieuse: Le traumatisme crânien léger. Presse de l’Université du Québec, Quebec.

https://doi.org/10.2307/j.ctv18pgq8f

[14] Conférence de consensus SRLF (1990) Traumatismes crâniens: Recommandations générales-classification de Masters. Société de Réanimation de Langue Française, Tours.

[15] Beaudeux, J.L. (2009) La protéine S100 B: Premier marqueur biologique pour le diagnostic du traumatisme crânien léger ou modéré. Annales Pharmaceutiques Française, 67, 187-194. https://doi.org/10.1016/j.pharma.2009.03.002

[16] Muballe, K.D., Sewani-Rusike, C.R., Longo-Mbenza, B. and Iputo, J. (2019) Predictors of Recovery in Moderate to Severe Traumatic Brain Injury. Journal of Neurosurgery, 131, 1648-1657. https://doi.org/10.3171/2018.4.JNS172185

[17] Ndabahweje, N. and Lelo, T. (2015) Principales pathologies cérébrales diagnostiquées au scanner à Goma. Revue médicale des Grands Lacs, 4, 137-147.

[18] Hode, L., Sogbo, D.H., Hounnou, M., Houessou, G.F., Voyeme, A.K.A. and Chobli, M. (2016) Prise en charge des traumatismes crânio-encéphaliques chez les enfants à Cotonou (Bénin). African Journal of Neurological Sciences, 35, 23-27.

[19] Bahloul, M., Chelly, H., Gargouri, R., Dammak, H., Kallel, H., Ben Hamida, C., Rekik, N., Ben Mahfoudh, K., Rebaii, R., Hachicha, M. and Bouaziz, M. (2009) Traumatismes crâniens dans le sud tunisien: Profil épidémiologique, manifestations cliniques et évolution. A propos de 454 cas. Tunisie Médicale, 87, 28-37. 